\title{
INTRASEXUAL COMPETITION AMONG HUMANS: PROSOCIAL TOWARDS THE OPPOSITE SEX AND PROSELF TOWARDS THE SAME SEX?
}

\author{
Grzegorz Pajestka \\ Opole University, Poland \\ E-mail: gpajestka@uni.opole.pl
}

\begin{abstract}
In a research conducted on a sample of participants from three countries $(N=256)$ : Poland, Ukraine and Denmark, a hypothesis of the moderating impact of other person sex on the level of social value orientation of men and women was tested. The study applied the now rarely used method of measuring social value orientation: the Warsaw Method, which was expected to reveal more subtle differences between men and women than those observed in the studies using the most popular social value orientation measurement tools, such as decomposed games. The direction of the observed relationship proved to be compatible with the predictions resulting from the phenomenon of intrasexual competition for a partner, however only in the case of men. Men were more prosocial in interaction with women than with other men, and more proself-interacting with men rather than women. Similar relationships assumed in the case of women were only partially confirmed: women were more pro-self in interaction with same-sex partners compared to interactions with opposite sex partners (however, the relationship was statistically significant only within the individualistic value orientation), but at the same time they were prosocial (but only within the cooperative value orientation).
\end{abstract}

Keywords: intrasexual competition, social value orientation, sex differences.

\section{Introduction}

Prosocial behaviour in humans can be considered in the context of intrasexual competition for partners. This is particularly noticeable in the attitude of males to other males - they are more competitive than towards females (Buunk, \& Massar, 2012) and more conciliatory towards women than men (Moskowitz, Sutton, Zuroff, \& Young, 2014). Men are also more generous in the presence of women (Saad, \& Gill, 2001) and are generally more likely to help others when they have an audience or helping is associated with risk (Eagly, 2009). In social psychology, this kind of behaviour of men towards women was considered as a remnant of the medieval knight's code which made men treat women in a special way, with courtesy (Glick \& Fiske, 2001). However, the greater heuristic value of the interpretation of this phenomenon derived from evolutionary psychology, where men's behaviour could be explained using the costly signalling theory (Smith \& Bird, 2000). This theory has derived directly from the handicap principle (Zahavi, 1975). According to this principle, altruistic behaviour is costly, therefore it is a valuable signal of males phenotypic as well as genetic quality: hence males' altruistic behaviours can be perceived as one of the mating strategies. In this context, it is easy to explain the greater tendency of men rather than women to express prosocial 
behaviours that require putting their life or health in danger. Competitive and altruistic behaviours appear as two sides of the same coin: they are a consequence of male struggle for resources, prestige, Vol. 11, No. 1, 2017 or recognition, which are especially appreciated by women in the process of sexual selection (e.g. Buss \&Schmitt, 1993). In this evolutionary context, however, it is difficult to embed prosocial and competitive behaviours of women. Competition is especially seen here as a "man's thing", which is difficult to find with such intensity in women as in men (cf. Buunk, \& Massar, 2012).

And, after all, the double process of sexual selection described by Darwin (1871) suggests that just as males fight with each other for females, females should fight with each other for male partners. The consequence of the double sexual selection, considered as the power forming human nature, should be widespread preference for behaviours related to the sex of an interaction partner: in the case of men greater prosocial behaviour towards women and, in the case of women - greater prosocial behaviour in relation to men. However, research on prosocial behaviour conducted in the context of social value orientation (defined as generalised preferences of distribution of goods between oneself and an interaction partner) did not confirm these assumptions. Comprehensive meta-analysis (Balliet, Li, Macfarlan, \& Van Vugt, 2011), including data from over a 50-year history of research in this area, which compares the 272 effect sizes, showed that interactions between men were based more on cooperation than interactions between women $(\mathrm{d}=.16)$. On the other hand, women are more likely to work in mixed pairs $(\mathrm{d}=-.22)$. In contrast, in the study conducted by Buunk \& Massar (2012), the immediate purpose of which was to review the assumptions about the male tendency to compete with men and to express prosocial behaviour in interactions with women, consistent with predictions based on the mainstream evolutionary approach was observed: the level of prosocial behaviour (cooperative value orientation) is higher when a man's partner is a woman, and when the partner is male, the competitive value orientation is dominant.

The differences in the results can probably be explained by the differences in the operationalisation of social value orientation (SVO) and, consequently, a variety of tools used to measure SVO. A meta-analysis conducted by Balliet et al. (2011) included research in which the measurement was made using social dilemmas (e.g. the prisoner's dilemma, the public goods dilemma). In the study of Buunk \& Massar one of the most popular methods of measuring social value orientation was used: the decomposed game. Although these two methods differ significantly, they are linked with their use of money (or points) as a representation of the goods. As it is clear from the research, the use of such representation enhances the tendency to compete (Grzelak, Poppe, Czwartosz, \& Nowak, 1988). It cannot be excluded that this is so mainly among men (competition for money is a stereotypically male field), which may lead to an erroneous assessment of social value orientation in women in the context of sex (which conforms to the stereotype that women are rather passive and submissive, the assumption of which is also present among scientists, cf. Hrdy, 1999). In addition, the studies based on the prisoner's dilemma measure two value orientations: cooperation and competition. Decomposed games include one value orientation more: individualism. Since men's behaviour towards women is explained as the result of altruism understood in the context of the costly signalling theory, it is worth including altruistic value orientation to the analysis. Meeting both these objectives is possible in the case of SVO measurement using the so-called Warsaw Method (Grzelak et al., 1988), which is used in this research to verify the following hypotheses:

H1: males are more prosocial (cooperative, but also altruistic, in their pattern of social value orientation) interacting with women rather than with men, and women in the interaction with men rather than with women $(\mathrm{H} 2)$

H3: males are more competitive and individualistic in interaction with other men than with women, and women in interaction with other women than with men (H4).

\section{Methodology of Research}

\section{General Background of Research}

The research was part of a wider project in which research in three countries was conducted: Poland, Denmark, and Ukraine. This enabled the universality/specificity of the predictions to be verified - at least in the context of the three examined cultures. In the study one of the versions 
of the Warsaw Method was used. The presentation of the Warsaw Method is taken from Szmajke and Zomerska (2003), since it seems to be the most clear and holistic (if needed, for more details see also Grzelak et al., 1988).

\section{Sample of Research}

The research involved 256 persons aged 17 to $28(\mathrm{M}=20.95, \mathrm{SD}=2.13)$ of which 84 people were Poles (43 men and 41 women) - they were students at Opole University of Technology; 83 people were Danes (40 men and 43 women) - they were students from the Roskilde University; 89 people were Ukrainians ( 45 men and 44 women) - they were students from the National University of the State Tax Service of Ukraine in Irpin and the Kyiv Slavonic University. The participants were randomly assigned to groups of varying stimulus material.

\section{Instrument and Procedures}

In this research, the value orientation was measured by presenting the participants with iconic images of faces: happy, neutral and sad, as in the example in Figure 1.

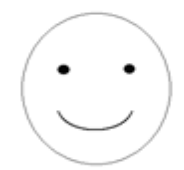

1

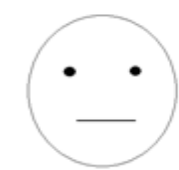

0

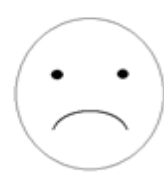

$-1$

Figure 1: The examples of iconic images of faces used in the research.

Each of the 9 presented offers consisted of two faces (one representing the participant, second representing his/her partner of interaction) as in the example in Figure 2.

1. (II)

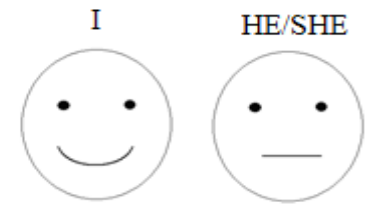

2. (VI)

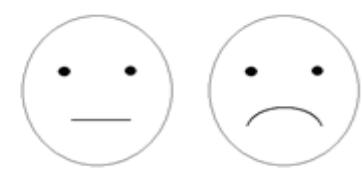

Figure 2: The examples of two from nine offers presented to participants.

The participants marked how satisfying each offer was for them on a scale, which was a 10-centimetre section. Given that the face icons were designated as in Figure 1, that is 1 (satisfaction), 0 (neutral), -1 (dissatisfaction), the offers evaluated by the participants can be represented as in Table 1.

Table 1. Numerical representation of the iconic offers presented to the participants. Notice: in the study each offer was represented by icons. For example: offers number two and four were represented by icons like presented in figure 1.

\begin{tabular}{cccccccccc}
\hline OFFER NO. & I & II & III & IV & V & VI & VII & VIII & IX \\
\hline I & 1 & 1 & 1 & 0 & 0 & 0 & -1 & -1 & -1 \\
HE/SHE & 1 & 0 & -1 & 1 & 0 & -1 & 1 & 0 & -1 \\
\hline
\end{tabular}


For each type of social value orientation, the ideal arrangement of the offers is different, as shown in Table 2. These arrangements reflect the definition properties of each value orientation types: in the case of individualistic to maximise their benefits regardless of the outcome of the interaction partner; in the case of cooperative - to maximise common benefits; in the case of competitive - to maximise the advantage over the partner; in the case of altruistic - to maximise the partner's result.

\section{Table 2. The ideal arrangement of the offers for four different social value orientations.}

\begin{tabular}{|c|c|}
\hline $\begin{array}{c}\text { THE MOST } \\
\text { ATTRACTIVE OFFER }\end{array}$ & THE LEAST ATTRACTIVE OFFER \\
\hline INDIVIDUALISM & $I=I I=I I I>I V=V=V I>V I I=V I I I=I X$ \\
\hline COMPETITION & III $>$ II $=\mathrm{VI}>\mathrm{I}=\mathrm{V}=\mathrm{IX}>\mathrm{IV}=\mathrm{VIII}>\mathrm{VI}$ \\
\hline COOPERATION & $I>I I=I V>V>V I=V I I I>I I I=V I I>I X$ \\
\hline ALTRUISM & $\mathrm{I}=\mathrm{IV}=\mathrm{VII}>\| \mathrm{I}=\mathrm{V}=\mathrm{VIII}>\mathrm{III}=\mathrm{VI}=\mathrm{IX}$ \\
\hline
\end{tabular}

The final step in the diagnosis of social value orientation in the Warsaw Method is computing (Spearman rank correlation with tie-correction) $)^{1}$ the similarity coefficient for the arrangement of offers of a participant with each of the four ideal arrangements (patterns of these ideal arrangements are shown in Table 2).

The arrangement of offers of each participant of the study was thus described with four correlation coefficients, hereinafter referred to as coefficients of social value orientation. In other words, the social value orientation of an individual is thus described by four correlation coefficients indicating the saturation of a social value orientation with components of individualism, competition, cooperation and altruism. These coefficients, which are dependent variables, were subject to further analysis in order to verify the relationships that were assumed.

The experimental manipulation consisted of sexual stigmatisation of the iconic images of the face: a participant was shown icons presenting the interaction partner as a "man" (in a male-male condition ${ }^{2}$ and female-male) or a "woman" (in female-female and male-female conditions), additionally described as "I" and "He" or "She" (Fig. 3). In the control condition the icons were devoid of sexual stigmatisation and a label of the interaction partner did not suggest their sex ("he/she").

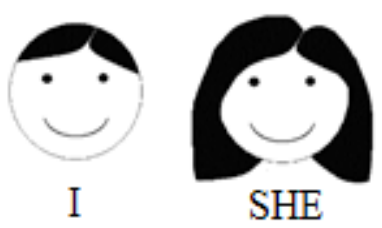

a)

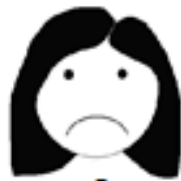

I

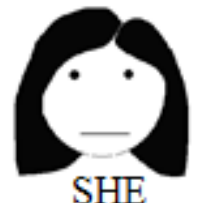

b)
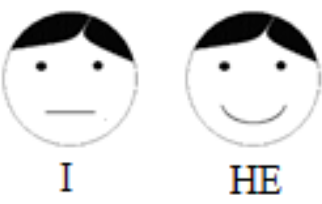

c)

Figure 3: The sample offers presented to the participants of the study: a) the male-female condition, b) the female-female condition, and (c) the male-male condition.

To sum up: nine offers were presented to each participant. Offers were consisted by icons: one representing the participant, second the hypothetical partner of the interaction. Attractiveness of each offer was evaluated by participants on scale. Participants' ratings were computed to give the coefficients of SVO. SVO coefficients (for individualism, competition, cooperation and altruism) were subjected to a further analysis as the dependent variables.

1 Analysing the data correlation coefficients subject to Fisher z-transformation was used (according to the formula: $z^{\prime}$ $=.5 \times[\ln (1+r)-\ln (1-r)]$, hence the values of the coefficients of each value orientation exceed " 1 " (absolute value).

2 In order to facilitate description, I used the following abbreviations for mean values in this text: $m-m$ : the male-male condition, m-f: male-female condition, m-con: male-control condition and similarly in the case of women. 


\section{Data Analysis}

Hypotheses one to four were examined in two steps: first by running MANOVAs with repeated measurements. Second by running four univariate ANOVAs to examine the effect of independent variables on each of the dependent variables separately. Statistica 12.5 was used for data analysis.

\section{Results of Research}

The multivariate analysis of variance with repeated measurements testing the relationship between social value orientations and independent variables showed no main effect of the sex of the participants: $\mathrm{F}(1,235)=.30, \mathrm{p}=.58$. However, the main effect of the partner's sex was significant: $F(2,235)=9.65, p<.001, \eta^{2}=.08$. It was the same with the effect of the country of origin of the participants: $\mathrm{F}(2,235)=6.91, \mathrm{p}<.001$. The interaction of these two variables ( sex and country of origin) was statistically non-significant: $\mathrm{F}(4,235)=1.58 \mathrm{p}=.18$. The participant's and partner's sex interaction was also non-significant: $\mathrm{F}(2,235)=.92, \mathrm{p}=.40$, as well as the interaction of a participant's sex and their country of origin: $\mathrm{F}(2,235)=.49, \mathrm{p}=.61$. The participant's sex and their country of origin and the partner's sex interaction was also not of significance: $F(16,709)=.15$, $p$ $=.96$. On the other hand, the analysis of the interaction of social value orientation coefficients (as the repeated measurements) and independent variables showed a variety of significant results. The interaction related directly to the proposed hypotheses was the one that took social value orientation coefficients, the sex of the partner and the sex of the participant into account: $F(6,705)=3,65, p<$ $.001 ; \eta^{2}=.003$. To examine the effect of independent variables on each of the dependent variables separately, the univariate tests were carried.

\section{Competitive Value Orientation and the Participant's and Partner's Sex}

The participant's and partner's sex interaction for competitive value orientation variable was statistically significant (ANOVA, $\left.\mathrm{F}(2,250)=4.13, \mathrm{p}<.01, \eta^{2}=.032\right)$. An analysis of simple effects did not confirm the predictions about the competitive value orientation of women: the difference between average competition values during interaction with a female partner and interaction with a male partner proved to be statistically non-significant $(\mathrm{ff}=0.38, \mathrm{fm}=0.29 ; \mathrm{d}=-.24)$. On the other hand, the predictions concerning men were proved: men's competition value was higher in interaction with another male partner $(\mathrm{mm})$ than with a female partner $(\mathrm{mf})$. The mean values were respectively: $\mathrm{mm}=0.38, \mathrm{mf}=0.13$ and the difference was statistically significant $(\mathrm{p}<.01$, $\mathrm{LSD}, \mathrm{d}=.68)$. In the control condition competition coefficients were independent of $\operatorname{sex}(\mathrm{m}=0.28$ vs. $\mathrm{f}=0.39, \mathrm{p}=.17)$.

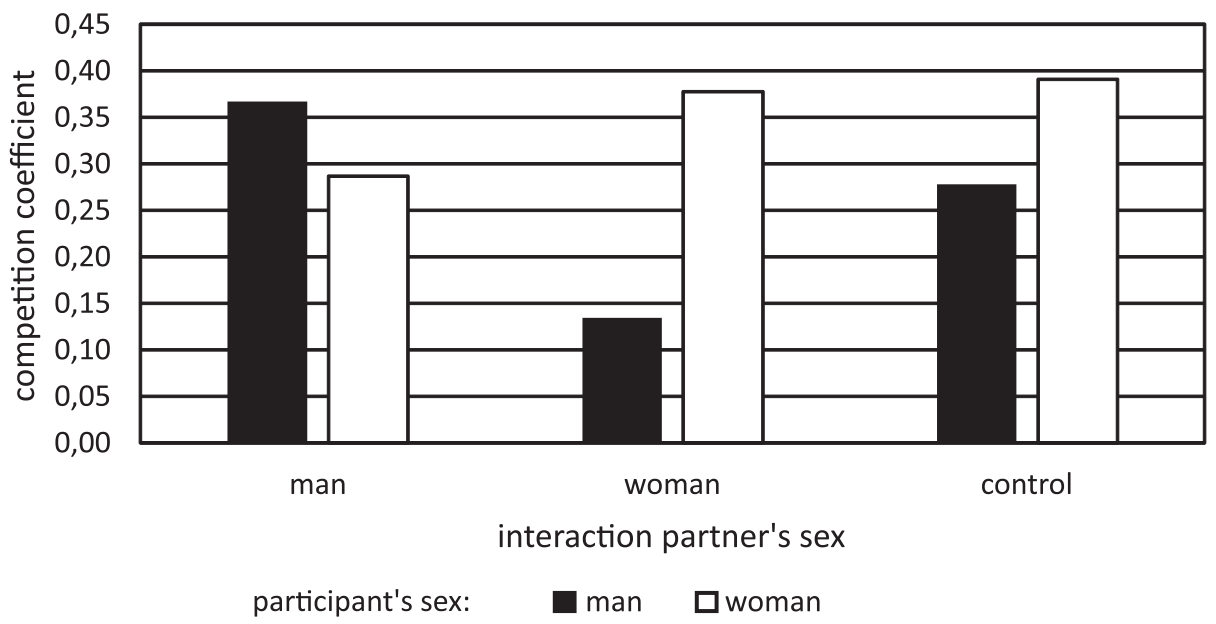

Figure 4: Dependency of the competition coefficient on the participant's and interaction partner's sex. 
The interaction of the sex of the participant and sex of the partner for individualism was statistically significant: $F(2,249)=3.69, p=.026, \eta^{2}=.029$. In the case of men interacting with a same-sex partner, the individualism coefficient was slightly higher than in the case of men interacting with an opposite sex partner $(\mathrm{mm}=0.95 \mathrm{vs} . \mathrm{mf}=0.83)$, but this difference was statistically non-significant ( $\mathrm{p}=.28, \mathrm{LSD}, \mathrm{d}=.23$ ). In the case of women, the individualism coefficient in the interaction with another woman turned out to be significantly higher than in the case of interaction with a man ( $\mathrm{fm}=0.87 \mathrm{vs}$. $\mathrm{ff}=1.16, \mathrm{p}<.006, \mathrm{LSD}, \mathrm{d}=-.69)$. In the control condition, the difference in individualism coefficient was statistically non-significant $(\mathrm{m}$-con $=1.02$ vs. $\mathrm{f}$-con $=1.13, \mathrm{p}=.29)$.

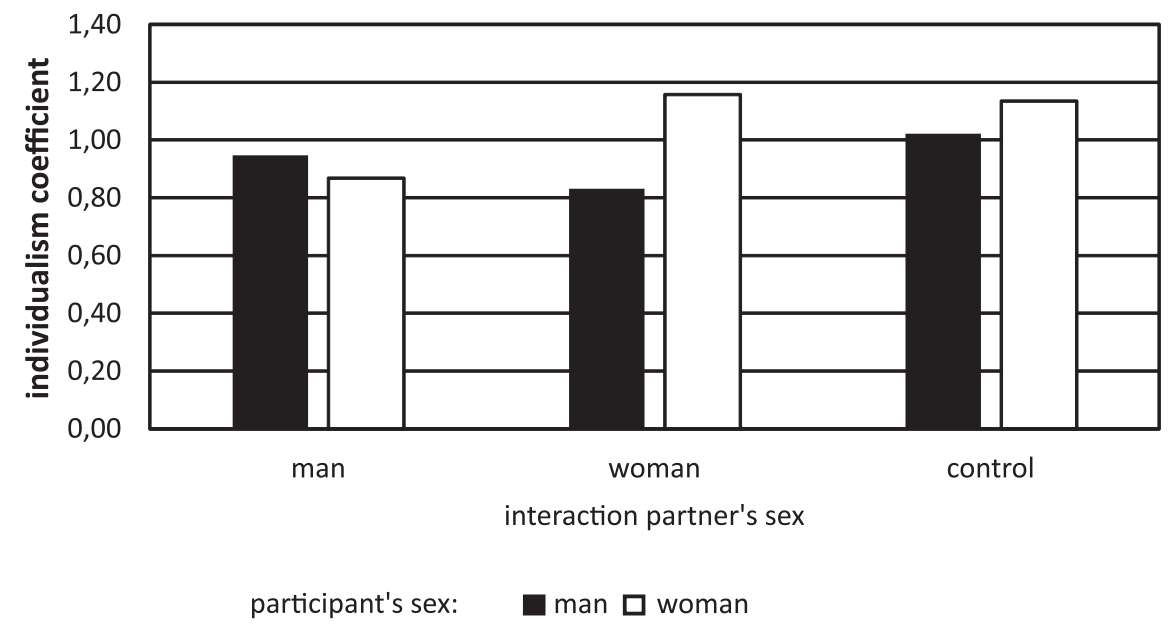

Figure 5: Dependency of the individualism coefficient on the participant's and partner's sex.

\section{Cooperative Value Orientation and the Participant's and Partner's Sex}

The interaction of sex of the participant and sex of the interaction partner with a cooperating value orientation proved to be statistically non-significant: $\mathrm{F}(2,250)=.11, \mathrm{p}=.89$.

The analysis of simple effects did not confirm the assumptions from hypothesis 2 that the cooperative value orientation in females would be stronger in interaction with a male partner than in interaction with a female partner ( $\mathrm{ff}=1.15$, vs. $\mathrm{fm}=0.85, \mathrm{p}<.01, \mathrm{LSD}, \mathrm{d}=.65)$. In the case of males, the cooperation coefficient measured in the interaction with another males $(\mathrm{mm})$ was substantially lower than the cooperation coefficient for men whose interaction partner was a woman $(\mathrm{mf}=1.20$ vs. $\mathrm{mm}=0.83, \mathrm{p}<.001, \mathrm{LSD}, \mathrm{d}=.66$ ). In the control condition, there were no differences between men and women in this coefficient $(\mathrm{m}=1.20, \mathrm{f}=1.07, \mathrm{p}=.69)$.

\section{Altruistic Value Orientation and the Participant's and Partner's Sex}

The interaction of the sex of the participant and the sex of the interaction partner was statistically significant for altruism: $\mathrm{F}(2,250)=3.97, \mathrm{p}<.05 \eta^{2}=.031$. In the case of males, the altruism coefficient was higher when their interaction partner was a woman than when it was a man $(\mathrm{mf}=$ 0.58 vs. $\mathrm{mm}=0.25, \mathrm{p}<.001, \mathrm{LSD}, \mathrm{d}=.80$ ). In the case of women, the altruism coefficient turned out to be similar regardless of whether the interaction partner was a woman or a man $(\mathrm{ff}=0.31$ vs. $\mathrm{fm}=0.33, \mathrm{p}=.86, \mathrm{LSD})$. In the control condition, there were no differences between men and women in this coefficient $(\mathrm{m}-\mathrm{con}=0.45$ vs. $\mathrm{f}$-con $=0.33 \mathrm{p}=.19)$. 
PROBLEMS

OF PSYCHOLOGY

IN THE $21^{\text {st }}$ CENTURY

Vol. 11, No. 1, 2017

48

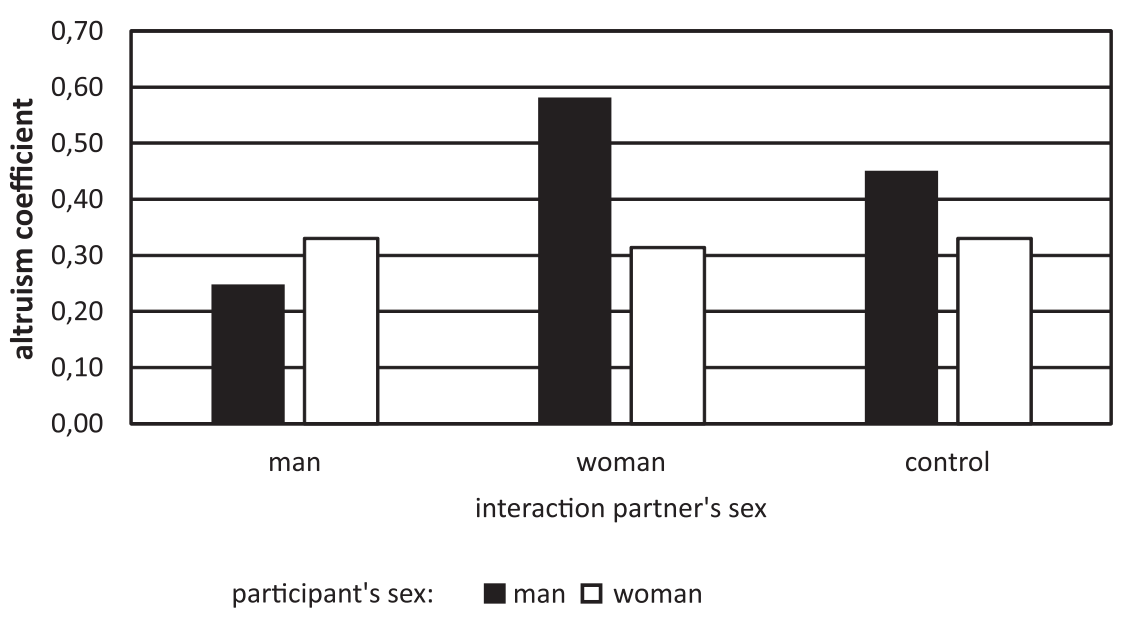

Figure 6: Dependency of altruism coefficient on the participant's and partner's sex.

\section{Cross-cultural Comparison}

To explore the cross-cultural differences, an analysis of variance for each dependent variable was carried out. It turned out that the interaction of the participants' country of origin, their sex and the sex of their partner (and thus the interaction which takes the probable dependencies in the intercultural context into account) is non-significant for each of the dependent variables. For competitive value orientation: $\mathrm{F}(4,238)=.33, \mathrm{p}=.86$; for individualistic value orientation: $\mathrm{F}(4$, $235)=.11, \mathrm{p}=.98$; for cooperative value orientation: $\mathrm{F}(4,238)=.12, \mathrm{p}=.98$; for altruistic value orientation $\mathrm{F}(4,238)=.73, \mathrm{p}=.57$. Thus, the country of origin had no apparent effect on the level of the SVO of the participants in the context of their sex and the sex of their partners.

\section{Discussion}

The research was designed to verify the assumptions about the difference in the social value orientation of men and women depending on the sex of their partner. The presented analyses show that the partner's sex acts as a facilitator of social value orientation. The result pattern emerging from these analyses is compliant with the predictions - men are more prosocial in interactions with women and less prosocial in interactions with another man, and more individualistic and competitive in interactions with other men then with a woman. This pattern is particularly visible in the case of competitive, altruistic and cooperative value orientation - here the differences between males interacting with a same-sex or opposite sex partner reached the level of statistical significance. In the case of individualistic value orientation, despite the fact that the significance level was not reached, the direction of the relationship was consistent with the predictions, and the differences between males were noticeable on the level of the size of the effect. Therefore, male prosociality in interaction with women has been further confirmed on the grounds of social value orientation. Similar results were also obtained by the aforementioned researchers, who verified their assumptions using another method - decomposed games (Buunk, \& Massar, 2012). These results can be explained based on the evolutionary psychology paradigm, the costly signalling theory in particular.

On the other hand, male prosociality towards women is sometimes explained differently and can be perceived as a consequence of benevolent sexism (Glick \& Fiske, 2001). A cultural norm ordering men to protect women and treat them with courtship was reflected in this study in the pattern of males' social value orientations: they were more prosocial and less competitive or individualistic in interactions with women rather than men. This prosociality would be the consequence of the patriarchal attitude of men associated with the stereotypical perception and treatment of women. If, however, the stereotypical perception would have an impact on the social value orientations of men in the interaction with women, this should be reflected in the results of the studies conducted in 
different countries. Denmark is, after all, a country where gender inequalities are much lower than Vol. 11, No. 1, 2017 in Poland, and in Poland they are lower than in Ukraine (cf. Human Development Reports: Gender Inequality Index - "United Nations Development Programme", 2016). However, in conducted analysis, which includes these three European countries, male prosociality in relationships with women is seen rather as a common characteristic of men, regardless of their country of origin. Of course, this individual result in limited intercultural context does not prejudge the universality of the observed phenomenon, however, together with the study of Buunk \& Massar (2012) it provides a consistent and theoretically justifiable conclusion. At this point, the theoretical assumption seems more consistent in the evolutionary psychology paradigm than in the social psychology paradigm.

Less consistent, however, are the results of females, at least in terms of the hypotheses made for the purpose of this paper. The competitive value orientation in females did not depend on the sex of their partner, although the direction of the relationship was consistent with the predictions and was noticeable at the level of the effect size. By contrast, in the interaction with other women their level of both cooperative and individualistic value orientation was higher (than in the interaction with men). It is difficult to find a meaningful theoretical justification for this discrepancy, hence it should stop with a conclusion that is not very original - that this requires further research. Buunk's \& Massar's (2012) conclusion on a higher individualistic value orientation in women than in men saying that it reflects the greater propensity of women to collect resources rather than to fight for them, is far from sufficient. It reflects a simplified belief that competition is characteristic for men, and affects women only to a small extent - limited mainly to the physical appearance (cf. Buss, 1988, Franzoi, 2001) ${ }^{3}$. In this context, a conclusion of $\operatorname{Hrdy}$ (1999), who believes that competition among female primates has been well documented excluding one species - humans, seems valuable. Furthermore, considering the possibility that the competition among women is subtler in nature than among men (cf. Campbell, 2002), it is advisable to use other methods of measuring social value orientation than the prisoner's dilemma or decomposed game. These should be methods which, on the one hand, focus less on economic goods and, on the other hand, are more sensitive to the variance of the results. These criteria are met by the Warsaw Method used in this study.

\section{Conclusions}

To sum up: a confirmation of the hypotheses applies to result pattern for males who are more prosocial in interactions with females than with other males, and more competitive and individualistic in interactions with males than with females. The inconsistency of the predictions with the results applies to the social value orientation of women. The pattern of these value orientations is incoherent and theoretically unclear. Its importance can be decrypted in subsequent research, in which the focus should be on the mechanism of the observed relationships. The lack of the identification of such a mechanism should undoubtedly be considered the weak side of this study.

\section{References}

Balliet, D., Li, N. P., Macfarlan, S. J., \& Van Vugt, M. (2011). Sex differences in cooperation: A meta-analytic review of social dilemmas. Psychological Bulletin, 137 (6), 881-909. https://doi.org/10.1037/a002535A4.

Buss, D. M., \& Schmitt, D. P. (1993). Sexual strategies theory: An evolutionary perspective on human mating. Psychological Review, 100 (2), 204-232. https://doi.org/10.1037/0033-295X.100.2.204.

Buss, D. M. (1988). The evolution of human intrasexual competition: Tactics of mate attraction. Journal of Personality and Social Psychology, 54 (4), 616-28. https://doi.org/10.1037/0022-3514.54.4.616.

Buunk, A. P., \& Massar, K. (2012). Intrasexual competition among males: Competitive towards men, prosocial towards women. Personality and Individual Differences, 52 (7), 818-821. https://doi.org/10.1016/j. paid.2012.01.010.

Campbell, A. (2002). A mind of her own: The evolutionary psychology of women. Oxford: Oxford University Press. http://dx.doi.org/10.1093/acprof:oso/9780198504986.001.0001.

\footnotetext{
${ }^{3}$ In this study, the error of such reasoning is visible in generally higher competitive value orientation of women than men: $F(1,250)=3.85, p=.05, \eta^{2}=.015$.
} 
Darwin, C. (1871). The descent of man, and selection in relation to sex. London: Murray. http://dx.doi. org/10.5962/bhl.title.2092.

Eagly, A. H. (2009). The his and hers of prosocial behavior: An examination of the social psychology of gender. American Psychologist, 34 (8), 644-658. https://doi:10.1037/0003-066X.64.8.644.

Franzoi, S. L. (2001). Is female body esteem shaped by benevolent sexism? Sex Roles, 44 (3-4), 177-188. http:// dx.doi.org/10.1023/A:1010903003521.

Glick, P., Fiske, S. (2001). An ambivalent alliance. Hostile and benevolent sexism as complementary justifications for gender inequality. American Psychologist, 56 (2),109-118. http://dx.doi.org/10.1037/0003066X.56.2.109.

Grzelak, J. L., Poppe, M., Czwartosz, Z., \& Nowak, A. (1988). "Numerical trap". A new look at outcome representation in studies on choice behaviour. European Journal of Social Psychology, 18 (2), 143-159. https://doi.org/10.1002/ejsp.2420180206.

Hrdy, S. B. (1999). The woman that never evolved. Cambridge: Harvard University Press.

Kuwabara, K. (2005). Nothing to fear but fear itself: Fear of fear, fear of greed and gender effects in two-person asymmetric social dilemmas. Social Forces, 84 (2), 1257-1272. https://doi.org/10.1353/sof.2006.0020.

Moskowitz, D. S., Sutton, R., Zuroff, D. C., \& Young, S. N. (2015). Fetal exposure to androgens, as indicated by digit ratios (2D:4D), increases men's agreeableness with women. Personality and Individual Differences, 75, 97-101. https://doi.org/10.1016/j.paid.2014.11.008.

Saad, G., \& Gill, T. (2001). Sex differences in the ultimatum game: An evolutionary psychology perspective. Journal of Bioeconomics, 3, 171-193. https://doi:10.1023/A:1020583425623.

Simpson, B. (2003). Sex, fear, and greed: A social dilemma analysis of gender and cooperation. Social Forces, 82 (1), 35-52. https://doi.org/10.1353/sof.2003.0081.

Smith, E. A., \& Bird, R. L. B. (2000). Turtle hunting and tombstone opening. Evolution and Human Behavior, 21 (4), 245-261. https://doi.org/10.1016/S1090-5138(00)00031-3.

Szmajke, A., Zomerska, J. (2003). Blaski i cienie rywalizacji. Orientacja społeczna a ustosunkowanie do innych ludzi, czyli: o dwóch typach egoizmu [Lights and shadows of competition. Social orientation and attitudes towards other people, that is: about two types of egoism]. In: J. Jonkisz i M. Lewandowski (Eds.), Wychowanie i kształcenie w reformowanej szkole (pp. 161-176). Wyd. WTN Wrocław.

Zahavi, A. (1975). Mate selection-A selection for a handicap. Journal of Theoretical Biology, 53 (1), 205-214. https://doi.org/10.1016/0022-5193(75)90111-3.

United Nations Development Programme. (2016). Human development reports 2015: Gender Inequality Index (GII). Retrieved from http://hdr.undp.org/en/composite/GII.

Received: November 19, 2017

Accepted: December 27, 2017
Grzegorz Pajestka

$\mathrm{PhD}$, Assistant Professor, Institute of Psychology, Opole University, Plac

Staszica 1, Opole, Poland.

E-mail: gpajestka@uni.opole.pl

Website: http://www.psychologia.uni.opole.pl 